\title{
Characterization of an aerodynamic lens for transmitting particles greater than 1 micrometer in diameter into the Aerodyne aerosol mass spectrometer
}

\author{
L. R. Williams ${ }^{1}$, L. A. Gonzalez ${ }^{2}$, J. Peck ${ }^{1}$, D. Trimborn ${ }^{3}$, J. McInnis ${ }^{4}$, M. R. Farrar ${ }^{5}$, K. D. Moore ${ }^{6}$, J. T. Jayne ${ }^{1}$, \\ W. A. Robinson ${ }^{1}$, D. K. Lewis ${ }^{1,7}$, T. B. Onasch ${ }^{1}$, M. R. Canagaratna ${ }^{1}$, A. Trimborn ${ }^{3}$, M. T. Timko ${ }^{1,8}$, G. Magoon ${ }^{1}$, \\ R. Deng ${ }^{9}$, D. Tang ${ }^{10}$, E. de la Rosa Blanco ${ }^{1}$, A. S. H. Prévôt ${ }^{11}$, K. A. Smith ${ }^{12}$, and D. R. Worsnop ${ }^{1}$ \\ ${ }^{1}$ Aerodyne Research, Inc., Billerica, MA, USA \\ ${ }^{2}$ CoolChip Technologies, Boston, MA, USA \\ ${ }^{3}$ AeroMegt, Hilden, Germany \\ ${ }^{4}$ Department of Chemistry, Northwestern University, Evanston, IL, USA \\ ${ }^{5}$ Cambridge Rindge and Latin High School, Cambridge, MA, USA \\ ${ }^{6}$ Space Dynamics Laboratory, Utah State University Research Foundation, North Logan, UT, USA \\ ${ }^{7}$ Department of Chemistry, Connecticut College, New London, CT, USA \\ ${ }^{8}$ Department of Chemical Engineering, Worcester Polytechnic Institute, Worcester, MA, USA \\ ${ }^{9}$ Institute of Bioengineering and Nanotechnology, Singapore \\ ${ }^{10}$ Dynamic Engineering Inc., Houston, TX, USA \\ ${ }^{11}$ Paul Scherrer Institute, Villigen, Switzerland \\ ${ }^{12}$ Department of Chemical Engineering, Massachusetts Institute of Technology, Cambridge, MA, USA
}

Correspondence to: L. R. Williams (williams@aerodyne.com)

Received: 3 March 2013 - Published in Atmos. Meas. Tech. Discuss.: 7 June 2013

Revised: 22 October 2013 - Accepted: 28 October 2013 - Published: 28 November 2013

\begin{abstract}
We have designed and characterized a new inlet and aerodynamic lens for the Aerodyne aerosol mass spectrometer (AMS) that transmits particles between $80 \mathrm{~nm}$ and more than $3 \mu \mathrm{m}$ in vacuum aerodynamic diameter. The design of the inlet and lens was optimized with computational fluid dynamics (CFD) modeling of particle trajectories. Major changes include a redesigned critical orifice holder and valve assembly, addition of a relaxation chamber behind the critical orifice, and a higher lens operating pressure. The transmission efficiency of the new inlet and lens was characterized experimentally with size-selected particles. Experimental measurements are in good agreement with the calculated transmission efficiency.
\end{abstract}

\section{Introduction}

A variety of aerosol characterization instruments have matured in the last decade. Of these, the Aerodyne aerosol mass spectrometer (AMS) is widely used to measure realtime, size-resolved chemical composition and mass loadings of ambient non-refractory aerosol particles (Canagaratna et al., 2007) and refractory black-carbon containing particles (Onasch et al., 2012). Aerosol particles are introduced into the AMS through a critical orifice at a flow of about $1.4 \mathrm{~cm}^{3} \mathrm{~s}^{-1}$ and focused into a narrow beam by an aerodynamic lens (Liu et al., 1995a, b). The particles are vaporized on a heated surface at $600^{\circ} \mathrm{C}$ or in a $\lambda=1064 \mathrm{~nm}$ intracavity laser. Vapor from the heated particles is ionized using $70 \mathrm{eV}$ electron impact, and the resulting mass-to-charge ratios $(m / z)$ for positive ions are analyzed by a quadrupole or time-of-flight mass spectrometer. The overall collection efficiency $(\mathrm{CE})$ for the AMS is $E_{\mathrm{L}} \times E_{\mathrm{B}} \times E_{\mathrm{S}}$, where $E_{\mathrm{L}}$ is the lens transmission efficiency, $E_{\mathrm{B}}$ represents reduced 
collection efficiency due to particle bounce off the vaporizer, and $E_{\mathrm{S}}$ represents reduced collection efficiency due to particle beam spreading for very small or very non-spherical particles (Huffman et al., 2005).

The aerodynamic lens currently used in the AMS, referred to as the standard lens, is based on a design described by Liu et al. (1995a, b), as modified in Zhang et al. (2002, 2004). The transmission efficiency of the standard lens is 1 between approximately $90 \mathrm{~nm}$ and $700 \mathrm{~nm}$ in vacuum aerodynamic diameter $\left(d_{\mathrm{va}}\right)$ and decreases to 0.3 at $1000 \mathrm{~nm}$ (Liu et al., 2007). The aerodynamic lens consists of a series of apertures that decrease in diameter. At each aperture, the gas streamlines are forced to the axial center line. After each aperture, the gas expands; however inertia tends to keep the particles near the center axis. Particles above a certain size are not focused effectively because their inertia is greater than the drag and they do not follow the gas streamlines to the center axis. Particles below a certain size are not focused because they either follow the gas streamlines or diffuse away from the center axis due to Brownian motion.

Several previous studies have addressed broadening the transmission size range of aerodynamic lenses. Wang and McMurry (2006) proposed using helium as the carrier gas to improve the transmission of small particles. Lee et al. (2009) invented a converging-diverging orifice to stabilize the fluid flow and transmit $5-50 \mathrm{~nm}$ particles better in air. The same group also developed an orifice configuration with descending-ascending diameters to achieve better transmission of large particles (Lee et al., 2013). Schreiner et al. (1999) experimentally demonstrated that a seven-stage high-pressure lens could focus micrometer-sized particles.

This paper presents the design and characterization of a new aerodynamic lens and inlet for the AMS that transmits particles up to several microns in diameter. Transmission of larger particles is achieved by increasing the pressure inside the aerodynamic lens from $173 \mathrm{~Pa}$ (1.3 Torr) in the standard lens to about $1840 \mathrm{~Pa}$ (13.8 Torr), following the concept described by Schreiner et al. (1999). The higher pressure increases the aerodynamic drag on the particles and allows larger particles to be focused to the center axis of the lens. Accordingly, the new lens design is referred to as the highpressure lens (HPL). In addition to the HPL, changes to the inlet, particularly the introduction of a relaxation chamber between the critical orifice and the aerodynamic lens (Wang and McMurry, 2006), increase the transmission of large particles. This inlet and lens will be useful for measuring ambient $\mathrm{PM}_{2.5}$ (particulate matter less than $2.5 \mu \mathrm{m}$ in diameter), detecting biological particles, characterizing drug delivery aerosols, and sampling high-density metal nanoparticles.

\section{Modeling of high-pressure lens and inlet}

Particle beam focusing relies on aerodynamic drag and the difference between the inertia of aerosol particles and the carrier gas. The Stokes number is the ratio of the particle stopping distance to a characteristic dimension of an obstacle (Hinds, 1999), or

$\mathrm{St}=\frac{\rho_{\mathrm{p}} d_{\mathrm{p}}^{2} C_{\mathrm{c}} u}{18 \mu d_{\mathrm{a}}}$,

where $\rho_{\mathrm{p}}\left(\mathrm{kg} \mathrm{m}^{-3}\right)$ is the particle density, $d_{\mathrm{p}}(\mathrm{m})$ the particle diameter, $C_{\mathrm{c}}$ the Cunningham slip factor, $u\left(\mathrm{~m} \mathrm{~s}^{-1}\right)$ the average fluid velocity at the lens aperture, $\mu\left(\mathrm{kg} \mathrm{m}^{-1} \mathrm{~s}^{-1}\right)$ the fluid viscosity, and $d_{\mathrm{a}}(\mathrm{m})$ the diameter of the lens aperture. Physically, St is interpreted as the particle's ability to respond to changes in the gas flow as the flow contracts and expands through each lens aperture. When $\mathrm{St} \ll 1$, particles will tend to follow the carrier gas streamlines. Conversely, when St $\gg 1$, inertia will tend to force particle trajectories to deviate from the carrier gas streamlines when the flow undergoes abrupt changes in direction. When $\mathrm{St} \sim 1$, particles tend to focus into a particle beam near the axis of the lens when the flow contracts and expands as it passes each aerodynamic lens aperture.

The concept of the high-pressure lens (HPL) is based on the loss of large particles due to their large inertia compared with the drag force exerted on them by the carrier flow. Large particles "slip" from the fluid streamlines, over-expand to impact the lens walls, and are lost. By increasing the pressure in each lens aperture, the Cunningham slip factor $C_{\mathrm{c}}$ decreases, which leads to an increase in drag force. As a result, large particles slip less at higher pressures and are transmitted through the lens with higher efficiencies (that is, St $\sim 1$ for larger particles). Smaller particles can still be transmitted at higher pressures at relatively high efficiencies by increasing the number of lens apertures. Detailed analysis of the effect of pressure on particle focusing and transmission has been discussed in the literature (Wang and McMurry, 2006) and is the subject of a separate manuscript in preparation (Peck et al., 2013).

The design of the HPL was developed using computational fluid dynamics (CFD) modeling to determine the transmission of particles as a function of particle diameter for different configurations. CFD modeling was performed using the ANSYS Fluent software package (ANSYS, 2012). First, the axisymmetric gas flow field and the pressure profile were calculated throughout the lens system, where the lens system includes the critical orifice holder, the relaxation chamber, the valve, and the aerodynamic lens (see Fig. 1). Ambient temperature and pressure were used as the inlet condition, and an outlet pressure of $0.001 \mathrm{~Pa}$ was used as the pressure in the vacuum chamber after the skimmer. The airflow is choked twice as it flows through the lens system - once at the critical orifice and once at the lens exit nozzle. The critical orifice 


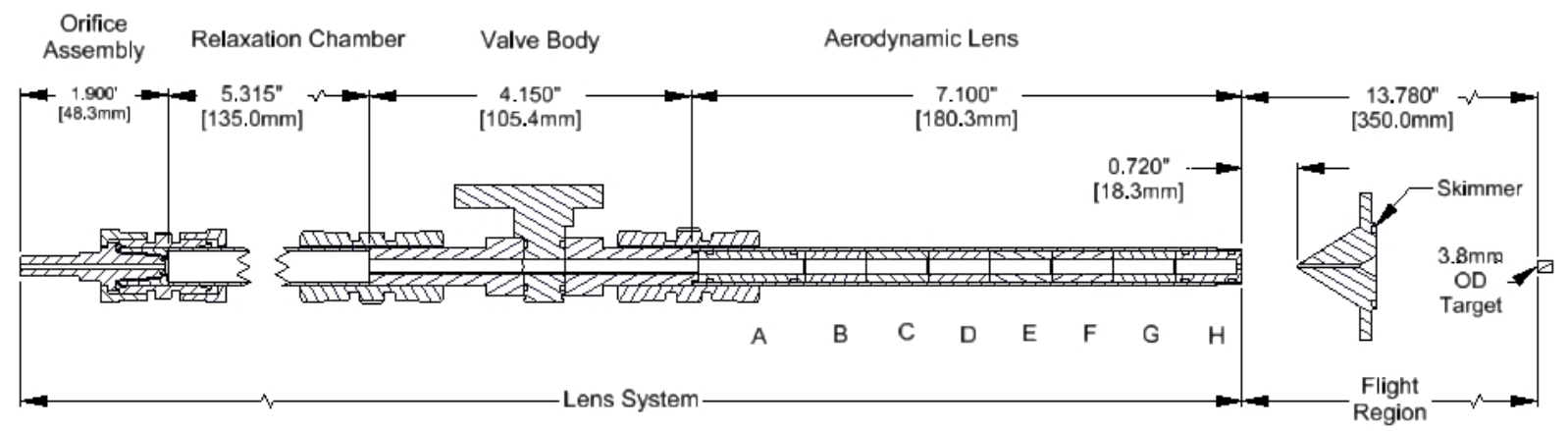

Fig. 1. Schematic of the lens system, including critical orifice assembly, relaxation chamber, valve and aerodynamic lens, and flight region to the vaporizer/target for the high-pressure lens in an aerosol mass spectrometer (not to scale).

diameter sets the mass flow rate, the nozzle diameter sets the pressure immediately upstream of the nozzle, and the seven lens orifices account for most of the pressure drop through the lens system.

After solving the 2-D axisymmetric flow profile, particles were injected upstream of the critical orifice into the gas flow field, and their trajectories were calculated. On the basis of their low concentration, particle-particle interactions were considered negligible and the potential influence of the particles on the gas flow was neglected. To obtain meaningful statistics, a total of 250 particle trajectories were calculated for each particle size, with all of the particles entering at the same axial position. Since the flow solution is axisymmetric and the flow profile at the injection site is not uniform, the inlet radial distribution of particles $f(r)$ was taken to be proportional to the local fluid velocity (Poiseuille flow) times the radius $r$, or

$f(r) \sim r\left[1-\left(\frac{r}{R}\right)^{2}\right]$

where $r(\mathrm{~m})$ is the radial position of the particle and $R(\mathrm{~m})$ is the radius of the tube. This radial position distribution accounts for the non-uniform fluid velocity profile as well as particles entering at different angular positions at a given radius. Particle drag forces and Brownian motion were calculated using the slip model proposed by Liu e al. (2007). Brownian motion in the lens system decreases the transmission of particles less than $100 \mathrm{~nm}$ in diameter, due to impaction loss in the lens system and due to broadening of the particle beam at the lens exit.

One change in the CFD modeling since the results in Liu et al. (2007) is the model of the vacuum chamber. When the flow exits the cone-shaped nozzle, the fluid undergoes a supersonic expansion into the vacuum chamber, and within a few nozzle diameters downstream, the pressure drops to less than $0.1 \mathrm{~Pa}\left(1 \times 10^{-3}\right.$ Torr $)$. Under these conditions, the mean free path of the gas molecules becomes comparable to the length scales in the vacuum chamber, and the continuum assumptions implicit in the CFD software are not valid. The approach in Liu et al. (2007) and Zhang et al. (2004) was to calculate particle trajectories with Fluent into the vacuum chamber and to use the beam broadening model in the vacuum chamber from Liu et al. (1995a) to correct for Brownian effects, assuming the pressure is $0.1 \mathrm{~Pa}\left(1 \times 10^{-3}\right.$ Torr $)$ throughout the vacuum chamber. In reality, the AMS vacuum chamber has a narrow channel (skimmer) located $18 \mathrm{~mm}$ past the lens exit. After the skimmer, the pressure drops to $0.001 \mathrm{~Pa}\left(1 \times 10^{-5}\right.$ Torr $)$. In the current model, the Fluent particle dynamics calculation (including Brownian motion) was truncated halfway between the lens exit nozzle and the skimmer. After this point, the particles were assumed to travel ballistically. The Fluent calculation was not terminated at the exit nozzle because there is still drag over the first few millimeters downstream of the nozzle while the flow transitions from the continuum to the kinetic regime. Ending the Fluent calculation at $z=0$, where $z$ is the axial distance from the exit nozzle into the vacuum chamber, underestimates the particle velocity for particles less than $2 \mu \mathrm{m}$ in diameter (see Fig. 2). Particles reach their terminal velocities after traveling about $5 \mathrm{~mm}$ into the vacuum chamber, and the Fluent solution terminated at $5 \mathrm{~mm}$ after the exit nozzle offers a good match with the experimentally measured particle velocities, as shown in Fig. 2. Terminating the Fluent solution $5 \mathrm{~mm}$ downstream of the nozzle provides the best tradeoff between capturing particle physics downstream of the nozzle and not using the CFD results at pressures where the continuum assumptions are invalid.

The axial and radial velocities at $5 \mathrm{~mm}$ were then used to calculate the trajectory of the particles towards the target. The lens transmission efficiency as a function of particle diameter, $E_{\mathrm{L}}\left(d_{\mathrm{p}}\right)$, between $30 \mathrm{~nm}$ and $20 \mu \mathrm{m}$ was calculated as the fraction of particles that pass through the lens system and impact the target, in this case representing the AMS vaporizer ( $3.8 \mathrm{~mm}$ diameter) located $350 \mathrm{~mm}$ from the lens exit (see Fig. 1). Spherical particles with unit density were used for the calculations.

The diameters of the exit nozzle and lens apertures were optimized by considering the tradeoff between the pressure in the lens and the size of the exit nozzle. The mass flow 
Table 1. Nominal diameters of apertures. Apertures A through $\mathrm{G}$ are $0.2 \mathrm{~mm}$ thick. Aperture $\mathrm{H}$ is a conical nozzle.

\begin{tabular}{lr}
\hline Aperture & $\begin{array}{r}\text { Nominal } \\
\text { ID (mm) }\end{array}$ \\
\hline A & 2.25 \\
B & 2.02 \\
C & 1.80 \\
D & 1.57 \\
E & 1.35 \\
F & 1.12 \\
G & 1.01 \\
H (exit nozzle) & 0.90 \\
\hline
\end{tabular}

rate into the lens is fixed by the $100 \mu \mathrm{m}$ diameter critical orifice. Higher pressure in the lens enhances the transmission of larger particles, and is achieved by decreasing the diameter of the exit nozzle. The smaller the exit nozzle, the more difficult it is to machine (see Sect. 4). In addition, higher lens pressure shifts the cutoff on the small particle side to larger particle diameters, detrimental for measuring ambient aerosol particle size distributions. The optimal configuration was determined to be a lens inlet pressure of around $1840 \mathrm{~Pa}$ (13.8 Torr), and an exit nozzle diameter of $0.9 \mathrm{~mm}$. The calculated pressure at the lens entrance and the calculated mass flow rate $\left(1.35 \mathrm{~cm}^{3} \mathrm{~s}^{-1}\right)$ are in good agreement with the experimentally measured values of 1730 to $1800 \mathrm{~Pa}$ (13 to 13.5 Torr) and $1.36 \mathrm{~cm}^{3} \mathrm{~s}^{-1}$, respectively.

The remaining aperture diameters were then determined by varying the ratio of lens apertures to the $0.9 \mathrm{~mm}$ exit nozzle to obtain the largest range of transmitted particle diameters. The nominal diameters of all the lens apertures in the final design are given in Table 1. The shape of the exit nozzle was also explored with CFD modeling. A cone-shaped nozzle with an entrance twice the diameter of the exit gave the best transmission for particles less than $150 \mathrm{~nm}$ in diameter.

Previous modeling work on the standard lens showed that the overall transmission of the lens system depends on the structures upstream of the aerodynamic lens (Liu et al., 2007). Accordingly, changes were made to each component in order to decrease particle losses. The critical orifice holder was redesigned to remove several step changes in internal diameter (ID) immediately downstream of the critical orifice; these steps were shown to be impaction sites in Liu et al. (2007). The new critical orifice holder expands to $10.2 \mathrm{~mm}$ ID at an angle of 80 degrees. The valve was redesigned to have a constant bore of $4.4 \mathrm{~mm}$ and consists of a custom valve body and a commercial valve stem. Similar to the critical orifice holder, CFD modeling showed that step changes of the ID around the commercially available valve used in the standard AMS lens system served as impaction sites. The constant bore valve improves the transmission efficiency for particles between $500 \mathrm{~nm}$ and $2 \mu \mathrm{m}$ in diameter.

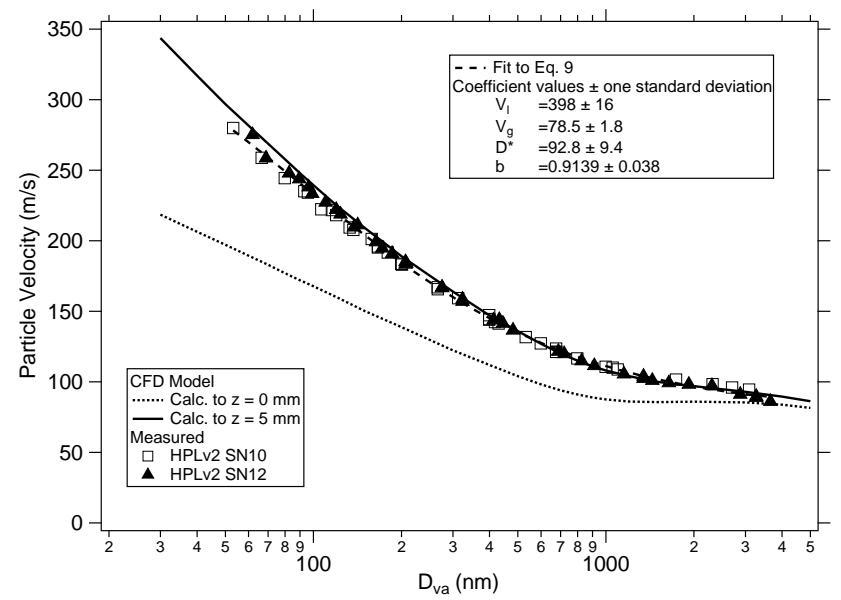

Fig. 2. Velocity as a function of particle diameter from CFD model with calculation ending at exit nozzle $(z=0$, dotted line) and calculation continuing $5 \mathrm{~mm}$ past exit nozzle $(z=5$, solid line). Experimentally determined particle velocity for two different highpressure lenses ( $\mathrm{SN} 10$, squares and $\mathrm{SN} 12$, triangles) and fit to Eq. (9) (dashed line). The fit parameters are defined in the text.

CFD simulations on the HPL with the constant bore valve predicted that an eddy would form downstream of the critical orifice holder and that this eddy could increase particle loss by impaction on the low-pressure side of the critical orifice or on the walls. Experimental observation of particle deposition on the back of the critical orifice was consistent with this loss mechanism. A relaxation chamber was therefore introduced between the critical orifice and the valve as suggested by Wang and McMurry (2006). The purpose of the relaxation chamber is to slow the larger particles and allow them to be entrained in the gas flow eddy behind the critical orifice. The optimal ID and length of the relaxation chamber were determined by examining calculated particle trajectories; the ID and length were increased until less than $5 \%$ of the particle trajectories impacted the back of the critical orifice or the walls of the relaxation chamber. A larger than necessary relaxation chamber is not desirable because it increases the residence time for particles in the lens system, possibly increasing evaporation of volatile components. The relaxation chamber in the current design increases the residence time in the lens system by roughly $50 \%$, from on the order of $0.04 \mathrm{~s}$ to $0.06 \mathrm{~s}$. Experimentally, minimal deposition of particles on the back of the critical orifice was observed with the relaxation chamber.

Figure 3 shows the calculated transmission efficiency for three cases: (1) with the relaxation chamber, calculated to $z=5 \mathrm{~mm}$ (solid line); (2) without the relaxation chamber, calculated to $z=5 \mathrm{~mm}$ (dashed line); and (3) with the relaxation chamber, calculated to $z=0 \mathrm{~mm}$ (dashdotted line). Comparing cases 1 (with, solid line) and 2 (without, dashed line) in Fig. 3 shows that the calculated transmission efficiency for particles greater than $1 \mu \mathrm{m}$ in 


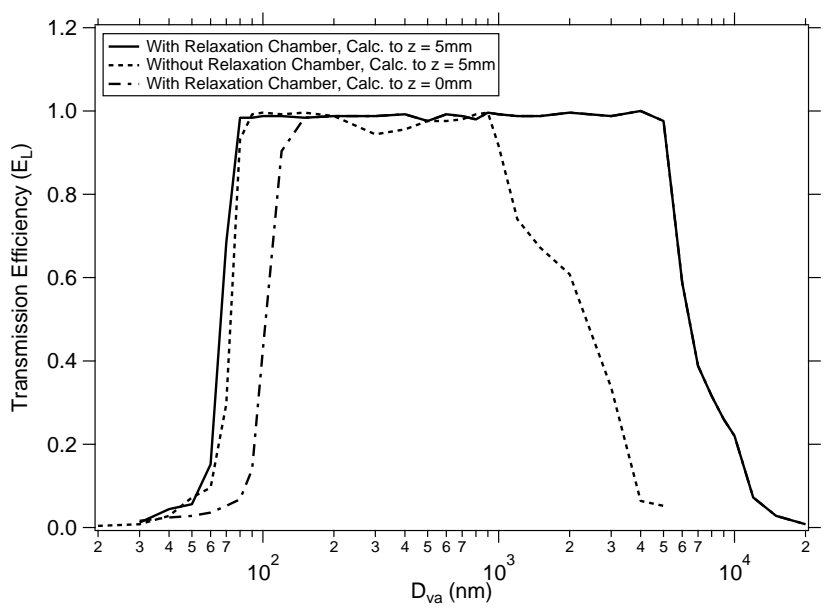

Fig. 3. Transmission efficiency $\left(E_{\mathrm{L}}\right)$ calculated by the CFD model as a function of particle size with the relaxation chamber, calculated to $5 \mathrm{~mm}$ past exit nozzle $(z=5$, solid line), without the relaxation chamber, calculated to $5 \mathrm{~mm}$ past the exit nozzle $(z=5$, dashed line), and with the relaxation chamber, calculated to the exit nozzle $(z=0$, dash-dotted line).

vacuum aerodynamic diameter is improved when the relaxation chamber is present. Comparing cases $1(z=5 \mathrm{~mm}$, solid line) and 3 ( $z=0$, dash-dotted line) shows that accurate modeling of the radial component of the drag force immediately downstream of the lens exit nozzle is important for predicting particle transmission in the $30-100 \mathrm{~nm}$ particle-size range. Extending the CFD calculation into the vacuum chamber increases the predicted transmission efficiency for particles between 60 and $100 \mathrm{~nm}$ and is in better agreement with the experimental measurements of $E_{\mathrm{L}}$ (see next section). The calculated $E_{\mathrm{L}}$ with the relaxation chamber and calculated to $z=5 \mathrm{~mm}$ are given in Table 2 .

\section{Experimental measurements}

\subsection{Transmission efficiency}

\subsubsection{Methods}

Experimental measurements of the transmission efficiency of the high-pressure lens and inlet were made at Aerodyne Research, Inc. using a quadrupole aerosol mass spectrometer (Q-AMS, Aerodyne Research, Inc., serial number, SN, 215058) equipped with a light scattering (LS) module (Jayne et al., 2000; Cross et al., 2007). The AMS operates in two modes: mass spectrum (MS) mode and particle time-of-flight (pToF) mode (Jiménez et al., 2003; Canagaratna et al., 2007). In pToF mode, transmission of the particle beam to the detector is modulated with a mechanical chopper rotating at 100$150 \mathrm{~Hz}$. The vacuum aerodynamic diameter $\left(d_{\mathrm{va}}(\mathrm{nm})\right)$ is calculated from the time delay between the chopper slit opening and the signal at the detector using a separately determined
Table 2. Calculated and experimental transmission efficiency, $E_{\mathrm{L}}$, for the high-pressure lens.

\begin{tabular}{|c|c|c|c|}
\hline $\mathrm{CFD} d(\mathrm{~nm})$ & CFD $E_{\mathrm{L}}$ & $\operatorname{Exp} d_{\mathrm{va}}(\mathrm{nm})$ & $\operatorname{Exp} E_{\mathrm{L}}$ \\
\hline 30 & 0.012 & 55 & $0.02 \pm 0.05$ \\
\hline 40 & 0.044 & 62 & $0.07 \pm 0.05$ \\
\hline 50 & 0.056 & 69 & $0.13 \pm 0.05$ \\
\hline 60 & 0.15 & 83 & $0.49 \pm 0.12$ \\
\hline 70 & 0.68 & 96 & $0.73 \pm 0.12$ \\
\hline 80 & 0.98 & 110 & $0.86 \pm 0.13$ \\
\hline 90 & 0.98 & 138 & $0.92 \pm 0.14$ \\
\hline 100 & 0.99 & 206 & $1.04 \pm 0.1$ \\
\hline 120 & 0.99 & 295 & $0.99 \pm 0.1$ \\
\hline 150 & 0.98 & 430 & $0.98 \pm 0.1$ \\
\hline 200 & 0.99 & 765 & $1.01 \pm 0.1$ \\
\hline 300 & 0.99 & 1200 & $1.02 \pm 0.12$ \\
\hline 400 & 0.99 & 1500 & $1.03 \pm 0.13$ \\
\hline 500 & 0.98 & 2000 & $1.06 \pm 0.14$ \\
\hline 600 & 0.99 & 3000 & $1.04 \pm 0.2$ \\
\hline 700 & 0.99 & & \\
\hline 800 & 0.98 & & \\
\hline 900 & 1.0 & & \\
\hline 1000 & 0.99 & & \\
\hline 1200 & 0.99 & & \\
\hline 1500 & 0.99 & & \\
\hline 2000 & 1.0 & & \\
\hline 3000 & 0.99 & & \\
\hline 4000 & 1.0 & & \\
\hline 5000 & 0.98 & & \\
\hline 6000 & 0.59 & & \\
\hline 7000 & 0.39 & & \\
\hline 8000 & 0.32 & & \\
\hline 9000 & 0.26 & & \\
\hline 10000 & 0.22 & & \\
\hline 12000 & 0.072 & & \\
\hline 15000 & 0.028 & & \\
\hline 20000 & 0.008 & & \\
\hline
\end{tabular}

velocity calibration (Sect. 3.2), where

$d_{\mathrm{va}}=\rho_{p} / \rho_{0} \times d_{\mathrm{m}} \times S$,

and $\rho_{\mathrm{p}}\left(\mathrm{g} \mathrm{cm}^{-3}\right)$ is the material density, $\rho_{0}\left(\mathrm{~g} \mathrm{~cm}^{-3}\right)$ unit density, $d_{\mathrm{m}}(\mathrm{nm})$ the mobility diameter and $S$ the empirically determined Jayne shape factor, which incorporates the effective particle density (Jayne et al., 2000; DeCarlo et al., 2004). For the transmission efficiency measurements presented here, all measurements were made in $\mathrm{pToF}$ mode with the quadrupole mass spectrometer set to a single mass.

Three different particle materials were used to cover a range of densities and shape factors (see Table 3): ammonium nitrate $\left(\mathrm{NH}_{4} \mathrm{NO}_{3}\right)$, sodium nitrate $\left(\mathrm{NaNO}_{3}\right)$ and polystyrene latex (PSL). Particles were generated with a TSI atomizer (Model 3076), dried in a diffusion dryer, size-selected with a differential mobility analyzer (TSI Model 3080L or Brechtel Model 2002), and detected with the Q-AMS and a condensation particle counter (CPC, TSI Model 3776) or an optical 
particle counter (OPC, Grimm Model 1.109). For particles with $d_{\mathrm{mob}}<250 \mathrm{~nm}$, the size distribution was measured with a scanning mobility particle sizer (SMPS, TSI Model 3936).

Two methods were used to experimentally determine $E_{\mathrm{L}}$ in the AMS with size-selected particles (Jayne et al., 2000; Liu et al., 2007). The first method was the single particle counting method. In pToF mode, particles that enter the AMS can be counted individually in two ways. First, individual particles can be counted with the mass spectrometer. Each vaporized particle produces a burst of ions at the monitored $m / z$. For $\mathrm{NH}_{4} \mathrm{NO}_{3}$ particles detected at $m / z 46$ (or $\mathrm{NaNO}_{3}$ particles detected at $m / z 30$ ), the ion signal for particles with $d_{\mathrm{m}}>100 \mathrm{~nm}$ will cross a threshold set just above the background noise and will be counted as individual particles. Second, single particles with $d_{\mathrm{m}}>250 \mathrm{~nm}$ can also be counted individually with the scattered light pulses in the LS module. The ratio of AMS counted particles (by MS or LS, in particles $\mathrm{cm}^{-3}$ ) to CPC counts (particles $\mathrm{cm}^{-3}$ ) gives $E_{\mathrm{L}}$ for that size:

$E_{\mathrm{L}}\left(d_{\mathrm{va}}\right)=\frac{\operatorname{Counts}_{\mathrm{AMS}}\left(d_{\mathrm{va}}\right)}{\operatorname{Counts}_{\mathrm{CPC}}\left(d_{\mathrm{va}}\right)}$.

The second method was the mass comparison method. Smaller particles $\left(d_{\mathrm{m}}<100 \mathrm{~nm}\right)$ do not create a sufficiently large ion signal to be counted individually with the mass spectrometer. However, the total particle mass for the ensemble can be accurately obtained by signal averaging (Jayne et al., 2000). In the mass method, the mass measured with the AMS is compared to the mass calculated for the number of particles counted by the CPC for a given $d_{\mathrm{va}}$.

$E_{\mathrm{L}}\left(d_{\mathrm{va}}\right)=\frac{\operatorname{Mass}_{\mathrm{AMS}}\left(d_{\mathrm{va}}\right)}{\operatorname{Mass}_{\mathrm{CPC}}\left(d_{\mathrm{va}}\right)}$

The CPC counts the total number of particles entering the AMS and was corrected for doubly and triply charged particles based on the SMPS scan. $\operatorname{Mass}_{\mathrm{CPC}}\left(d_{\mathrm{Va}}\right)\left(\mu \mathrm{g} \mathrm{m}^{-3}\right)$ is calculated from the number of singly charged particles (Counts ${ }_{\mathrm{CPC}}$, particles $\left.\mathrm{cm}^{-3}\right), d_{\mathrm{m}}(\mathrm{nm})$ selected by the DMA, the material density $\left(\rho_{\mathrm{p}}, \mathrm{g} \mathrm{cm}^{-3}\right)$ and the Jayne shape factor $(S)$ for the particle composition:

$\operatorname{Mass}_{\mathrm{CPC}}\left(d_{\mathrm{va}}\right)=10^{-9} \operatorname{Counts}_{\mathrm{CPC}} \frac{\pi}{6}\left\langle d_{\mathrm{m}}\right\rangle^{3} \rho_{\mathrm{p}} S$,

where the factor of $10^{-9}$ accounts for unit conversion.

When doubly or triply charged particles pass through the DMA, the pToF mode is used to separate the different size modes in the AMS signal. An effective mass to ion ratio (EMI, $\mu \mathrm{g} \mathrm{m}^{-3} \mathrm{~Hz}^{-1}$ ) was used to convert the AMS ion signal at a single fragment $m / z$ to total particle mass for the singly charged particles. The EMI for $\mathrm{NH}_{4} \mathrm{NO}_{3}$ at $m / z=46$ was obtained at $d_{\mathrm{m}}=300 \mathrm{~nm}$, where the AMS and CPC count rates matched (i.e., $E_{\mathrm{L}}=1$ )

$\mathrm{EMI}=\frac{\operatorname{Mass}_{\mathrm{CPC}}(300 \mathrm{~nm})}{\operatorname{AMS}_{i}(300 \mathrm{~nm})}$,
Table 3. Properties of materials used for the transmission efficiency experiments.

\begin{tabular}{lrrrr}
\hline & $\begin{array}{r}\text { Density } \\
\left(\mathrm{g} \mathrm{cm}^{-3}\right)\end{array}$ & $\begin{array}{r}\text { Jayne shape } \\
\text { factor }(S)\end{array}$ & $\begin{array}{r}\text { Vaporizer } \\
T\left({ }^{\circ} \mathrm{C}\right)\end{array}$ & $\begin{array}{r}\text { Detected } \\
m / z\end{array}$ \\
\hline $\mathrm{NH}_{4} \mathrm{NO}_{3}$ & 1.72 & 0.8 & $\sim 600$ & 46 \\
$\mathrm{NaNO}_{3}$ & 2.26 & 0.85 & $\sim 800$ & 30 \\
$\mathrm{PSL}$ & 1.05 & 1 & $\sim 900$ & 104 \\
\hline
\end{tabular}

where $\mathrm{AMS}_{i}\left(\mathrm{~Hz}\right.$ or ions s $\mathrm{s}^{-1}$ ) is the ion signal at $m / z=46$.

The transmission efficiency, $E_{\mathrm{L}}\left(d_{\mathrm{va}}\right)$, using the mass comparison method was determined by making simultaneous AMS, CPC and SMPS measurements of DMA size-selected particles and using the equation for the mass of singly charged particles at $d_{\mathrm{va}}$ :

$E_{\mathrm{L}}\left(d_{\mathrm{va}}\right)=\frac{\operatorname{Mass}_{\mathrm{AMS}}\left(d_{\mathrm{va}}\right)}{\operatorname{Mass}_{\mathrm{CPC}}\left(d_{\mathrm{va}}\right)}=\frac{\operatorname{EMI} \times \operatorname{AMS}_{i}\left(d_{\mathrm{va}}\right)}{\operatorname{Mass}_{\mathrm{CPC}}\left(d_{\mathrm{va}}\right)}$,

where Mass ${ }_{\mathrm{CPC}}$ is defined in Eq. (6).

Using the mass comparison method to measure $E_{\mathrm{L}}$ assumes that the bounce $\left(E_{\mathrm{B}}\right)$ and particle beam spreading $\left(E_{\mathrm{S}}\right)$ contributions to AMS collection efficiency are negligible. For the sizes of $\mathrm{NH}_{4} \mathrm{NO}_{3}$ particles used $\left(d_{\mathrm{va}}=50\right.$ to $300 \mathrm{~nm}), E_{\mathrm{B}}=1$ and, therefore, particle bounce does not decrease the collection efficiency. Aerodynamic lenses focus larger particles more tightly than smaller particles. For very small particles (i.e., with $d_{\mathrm{va}}<70 \mathrm{~nm}$ ), the particle beam diameter can be larger than the vaporizer diameter, causing a decrease in collection efficiency $\left(E_{\mathrm{S}}<1\right)$. We have not applied a correction for $E_{\mathrm{S}}$ to the data presented here because the $\mathrm{CE}$ for particles smaller than $70 \mathrm{~nm}$ is already small $(<0.2)$ and the correction is probably less than $20 \%$ and not well-quantified. The CFD model results indicated that particle beam spreading decreases $\mathrm{CE}$ for particle sizes smaller than 60 or $70 \mathrm{~nm}$ by 10 to $20 \%$. In addition, experimental results for $40 \mathrm{~nm}$ particles with a similar standard lens in Liu et al. (1995b) suggest a $10 \%$ decrease in CE for the AMS detector geometry (Huffman et al., 2005).

All particle concentrations were well above the AMS detection limit. For example, for $\mathrm{NH}_{4} \mathrm{NO}_{3}$ particles with $d_{\mathrm{m}}=$ $55 \mathrm{~nm}$, the number of particles used would provide a signalto-noise ratio (SNR) of $\sim 70$ over $1 \mathrm{~min}$ of averaging. For larger sizes, the concentration required for a SNR of 2 falls quickly to $\sim 1 \mathrm{~cm}^{-3}$, and the concentrations used were well above this. This estimate provides a check to show that if particles were not detected, it was due to $E_{\mathrm{L}}$ rather than the detection sensitivity of the mass spectrometer.

\subsubsection{Results}

The experimentally measured transmission efficiencies are presented in Fig. 4. The mass method was used for $\mathrm{NH}_{4} \mathrm{NO}_{3}$ particles with $d_{\mathrm{va}}<300 \mathrm{~nm}$. Measurements for two different HPLs (closed triangles SN12, open triangles SN13) are 
in good agreement with one another. Between $d_{\mathrm{va}}=130 \mathrm{~nm}$ and $1400 \mathrm{~nm}$, the count method was used with $\mathrm{NH}_{4} \mathrm{NO}_{3}$ and $\mathrm{NaNO}_{3}$ particles. Particles were counted with a $\mathrm{CPC}$ at the entrance to the AMS and counted with both the mass spectrometer and light scattering after passing through the lens system. Under some conditions, particles have been observed to bounce off the vaporizer in the AMS (Quinn et al., 2006; Matthew et al., 2008), thus decreasing the MS counts relative to the LS counts. In these experiments, good agreement between mass spectrometer particle counts and light scattering particle counts for $\mathrm{NH}_{4} \mathrm{NO}_{3}$ indicates that particle bounce off the vaporizer was minimal, and only MS counts are shown in Fig. 4 (closed squares SN12, open squares SN13). For NaNO3, MS counts were typically 10 to 20 percent lower than LS counts, indicating some particle bounce. Since the goal is to measure the lens transmission efficiency, only the data for $\mathrm{LS}$ counting of $\mathrm{NaNO}_{3}$ particles are shown in Fig. 4 (closed circles SN12, open circles SN13). Similar transmission efficiencies $\left(E_{\mathrm{L}}>50 \%\right.$ for $d_{\mathrm{va}}$ between $100 \mathrm{~nm}$ and $3 \mu \mathrm{m}$ ) were measured for a third high-pressure lens (SN10) and are shown in Fig. 4 without error bars and with a single symbol for all three methods (grey stars) in order to simplify the figure.

For particles with $d_{\mathrm{va}}>1400 \mathrm{~nm}$, the CPC undercounted particles and the undercounting increased with increasing particle size. Presumably, particles in this size range are lost inside the CPC due to impaction. For this size range and $\mathrm{SN} 12$, we instead used a Grimm OPC to count the particles entering the AMS. The Grimm OPC is designed to count particles between $250 \mathrm{~nm}$ and $32 \mu \mathrm{m}$ in diameter. We split the flow from the DMA with a wye between the OPC $\left(200 \mathrm{~cm}^{3} \mathrm{~min}^{-1}\right)$ and the AMS $\left(85 \mathrm{~cm}^{3} \mathrm{~min}^{-1}\right)$ and added filtered makeup air to bring the OPC inlet flow to $1.2 \mathrm{~L} \mathrm{~min}{ }^{-1}$. We used a Brechtel DMA because it can select particles with larger mobility diameters than the TSI DMA. PSL particles were measured without passing through a DMA and were counted only with light scattering in the AMS due to significant bouncing from the vaporizer. The small surfactant particles associated with generating PSLs in an atomizer were discriminated against by size in both the AMS and the OPC. Note that the data points for SN10 and SN13 for $d_{\mathrm{va}}>1400 \mathrm{~nm}$ were measured using a CPC. These points have been corrected for the CPC undercounting with a correction factor determined by comparing CPC counts and OPC counts for particles in this size range.

The error bars on the experimental points determined by the mass method are estimated from the uncertainty in EMI ( $\pm 15 \%)$, CPC counts $( \pm 5 \%)$, and $d_{\mathrm{m}}( \pm 5 \mathrm{~nm})$. The error due to ion counting statistics in the mass spectrometer was negligible. The error bars in the count method are determined from the standard deviation in the CPC and AMS particle counts for 1 min averages, typically $\pm 5 \%$ and $\pm 8 \%$, respectively. At least 2000 particles were counted for each point. The error bars are much larger when counting with the OPC because particle concentrations were low $(\sim 50$ to

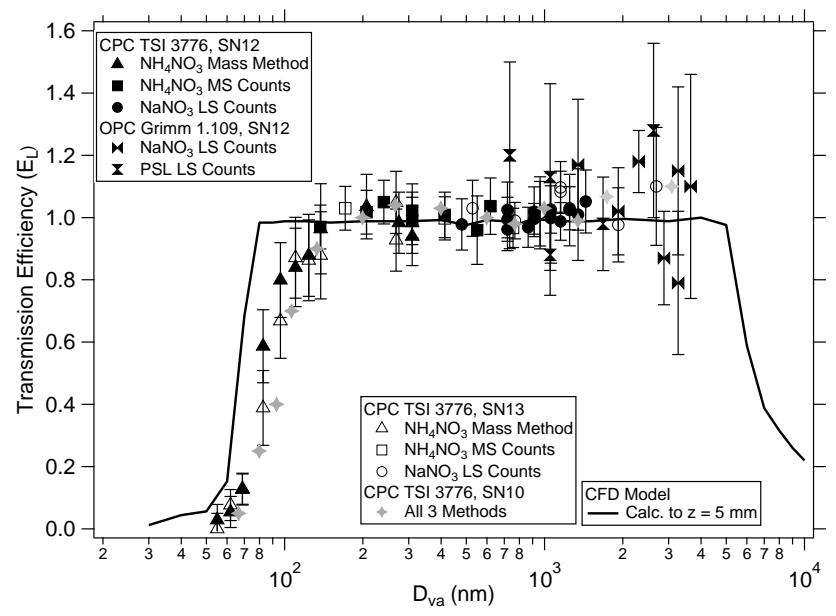

Fig. 4. Experimentally determined transmission efficiency $\left(E_{\mathrm{L}}\right)$ as a function of particle size for three examples of the HPL (SN10, SN12 and SN13), using the mass method (triangles) and the count method (other symbols). Particles entering the AMS were counted with a CPC or an OPC, and particles transmitted by the lens system were measured with the mass spectrometer or with light scattering signals. The CFD calculation (extending to $z=5 \mathrm{~mm}$ past the exit nozzle) is shown with the solid line.

$100 \mathrm{p} \mathrm{cm}^{-3}$ ) for these large sizes and each point corresponds to a total of 200 to 300 particles.

Figure 4 shows that the lens transmission efficiencies measured for three different examples of the HPL (SN10, SN12 and SN13) are in good agreement and demonstrate $E_{\mathrm{L}}>50 \%$ between approximately $d_{\mathrm{va}}=80 \mathrm{~nm}$ and $d_{\mathrm{va}}>3 \mu \mathrm{m}$. The experimental $E_{\mathrm{L}}$ points are given in Table 2 as averages in size bins centered on the $d_{\mathrm{va}}$ in the table.

\subsection{Particle velocity}

Particle velocities were determined experimentally from the particle time of flight divided by the path length between the chopper and the vaporizer. Particle time of flight was measured at the peak of the time-resolved mass signal at $m / z=46$ for $\mathrm{NH}_{4} \mathrm{NO}_{3}$ and at $m / z=30$ for $\mathrm{NaNO}_{3}$. Results for two different HPLs (SN10 and SN12) are in good agreement with each other and with the CFD model calculations as shown in Fig. 2. The particle velocity, $v\left(\mathrm{~m} \mathrm{~s}^{-1}\right)$, in the AMS is fit with an empirical equation (Allan et al., 2003):

$v=v_{1}+\left(v_{\mathrm{g}}-v_{\mathrm{l}}\right) /\left(1+\left(d_{\mathrm{va}} / d^{*}\right)^{b}\right)$,

where $v_{1}\left(\mathrm{~m} \mathrm{~s}^{-1}\right)$ represents the gas velocity in the lens, $v_{\mathrm{g}}$ $\left(\mathrm{m} \mathrm{s}^{-1}\right)$ the gas velocity at the lens exit, and $d^{*}(\mathrm{~nm})$ and $b$ the fitting parameters. The fitting parameters for the HPL are given in Fig. 2. Note that the particle velocities are higher with the HPL than with the AMS standard lens due to the higher pressure behind the supersonic expansion into the vacuum chamber. 
Table 4. Measured and calculated particle beam widths.

\begin{tabular}{lrrr}
\hline & $\begin{array}{r}\text { BWP-HPL } \\
\sigma\end{array}$ & $\begin{array}{r}\text { Calculated } \\
\sigma\end{array}$ & $\begin{array}{r}\text { Standard } \\
\text { lens } \sigma^{*}\end{array}$ \\
\hline $102 \mathrm{~nm} \mathrm{PSL}_{300 \mathrm{~nm} \mathrm{NH}_{4} \mathrm{NO}_{3}}$ & $0.4 \pm 0.1$ & 0.35 & 0.3 \\
$500 \mathrm{~nm} \mathrm{NH}_{4} \mathrm{NO}_{3}$ & $0.1 \pm 0.1$ & 0.11 & 0.18 \\
\hline
\end{tabular}

* Huffman et al. (2005)

\subsection{Particle beam width}

Particle beam widths were measured at three particle sizes using a beam width probe (BWP) (Huffman et al., 2005). The BWP passes a vertical, $0.5 \mathrm{~mm}$ wide wire through the particle beam, stopping at fixed horizontal locations. The attenuation in particle signal was recorded as a function of wire position, and the particle beam width was determined using the model in Huffman et al. (2005). Particle beam widths, reported as $\sigma$ for a one-dimensional Gaussian, are given in Table 4 for $100 \mathrm{~nm}$ PSL particles, and size-selected $d_{\mathrm{m}}=300$ and $500 \mathrm{~nm} \mathrm{NH}_{4} \mathrm{NO}_{3}$ particles. The measured values are in good agreement with the beamwidth determined from the CFD model by calculating the arrival positions at the target (vaporizer) of 100 particles at each size. The particle beam widths are similar to those measured for the standard lens for $100 \mathrm{~nm}$ PSLs and $d_{\mathrm{m}}=300 \mathrm{~nm} \mathrm{NH} \mathrm{NO}_{3}$ particles (Huffman et al., 2005).

\section{Machining the high-pressure lens}

The small aperture sizes in the HPL are difficult to machine. If the apertures are not centered on the lens axis or are not perfectly round, they can distort the gas flow field and therefore the particle trajectories. We tested the quality of the lens apertures by observing the deposition of polydisperse $\mathrm{NH}_{4} \mathrm{NO}_{3}$ particles that have been transmitted by the lens system and impact the end of an acrylic rod that has been positioned in the AMS vacuum chamber in place of the heated tungsten vaporizer. The deposition pattern for HPL SN10 is a long streak (Fig. 5a), indicating that different size particles are focusing to different downstream radial positions, while the pattern for HPL SN12 is circular (Fig. 5b), indicating that different size particles are focused along the centerline of the lens. From deposition patterns of size-selected particles, we have determined that the diffuse region corresponds to approximately 60 to $70 \mathrm{~nm}$ particles, the brightest part to $300 \mathrm{~nm}$ particles and the narrow tail to $600 \mathrm{~nm}$, as indicated by the numbers in Fig. 5a. Particle concentrations for sizes greater than $600 \mathrm{~nm}$ were too low to observe in the deposition patterns for polydisperse distributions shown in Fig. 5. Visual inspection of the apertures under a microscope showed defects along the edges of the SN10 apertures and nozzle that are likely the sources of the poor focusing.
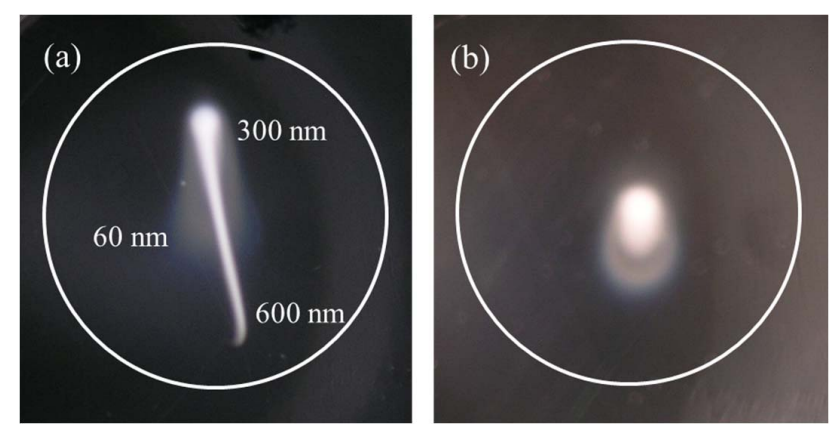

Fig. 5. Deposition patterns of polydisperse $\mathrm{NH}_{4} \mathrm{NO}_{3}$ transmitted by the lens system for (a) HPL SN10 and (b) HPL SN12. The white circle represents the size of the vaporizer. The numbers are approximate particle sizes for different parts of the deposition pattern based on measurements with size-selected particles.

Traditional machining techniques, such as drilling the aperture holes, were unsuccessful in making apertures that could focus a broad range of particle sizes into a narrow beam. Electrical discharge machining (EDM) for the apertures was more successful. For example, in a set of five lenses machined using EDM, two gave compact deposition patterns like Fig. 5b, two gave dispersed deposition patterns like Fig. 5a, and one gave an intermediate deposition pattern. We have experimented with using aluminum instead of stainless steel for the apertures and lens tube and found a similar success rate. The straightness of the lens tube into which the apertures are inserted is also important. We used heattreating and annealing of the aluminum lens tubes to improve straightness. We continue to refine the machining specifications so that we can consistently obtain deposition patterns like the one for SN12.

Imperfections in the machining of the lens apertures are also likely the source of the disagreement in $E_{\mathrm{L}}$ below $d_{\mathrm{va}}=150 \mathrm{~nm}$ between the CFD model and the measurements (see Fig. 4). The CFD model is axisymmetric and thus cannot capture the effect of apertures that are not centered or not round. Disturbances in radial and azimuthal flow due to aperture imperfections do not significantly affect the path of larger particles, as these tend to be tightly focused near the lens axis after they pass the first few lens apertures. Smaller particles, especially those with $d_{\mathrm{va}}<150 \mathrm{~nm}$, are on average much further away from the lens axis due to Brownian diffusion and are more sensitive to radial and azimuthal disturbances that are not captured by the axisymmetric CFD model. Small particles are especially sensitive to exit nozzle imperfections, as no downstream lens apertures can recollimate the particle beam if it is de-focused in the exit nozzle. As we improved the machining specifications, the measured $E_{\mathrm{L}}$ approached the calculated values. For example, the measured $E_{\mathrm{L}}$ for $\mathrm{SN} 10$ (see Fig. 4) was lower for particles with $d_{\mathrm{va}}<150 \mathrm{~nm}$ than $E_{\mathrm{L}}$ for SN12. The measured 
$E_{\mathrm{L}}$ for $\mathrm{SN} 10$ for larger particles ( $200 \mathrm{~nm}$ to $3 \mu \mathrm{m}$ ) was the same as SN12 as long as the lens was re-aimed twice (at $d_{\mathrm{va}}=700 \mathrm{~nm}$ and $d_{\mathrm{va}}=1.5 \mu \mathrm{m}$ ) so that the particles reached the detector.

\section{Comparison with other high-pressure lens measurements}

Schreiner et al. (1999) have published transmission efficiency measurements for two aerodynamic lenses that operate at pressures from 1333 to $20000 \mathrm{~Pa}$ (10 to 150 Torr). They reported transmission efficiencies $>90 \%$ for the size range $340 \mathrm{~nm}$ to $3 \mu \mathrm{m}$ with the detector located $100 \mathrm{~mm}$ from the lens exit. The Schreiner et al. (1999) results are consistent with the transmission efficiencies reported here for this high-pressure lens. The Schreiner lens is not, however, useful for the AMS because the particle beam divergence is too high. If the Schreiner lens particle beam traveled the $350 \mathrm{~mm}$ to the AMS detector, the particle beam width would be much larger than the diameter of the vaporizer for most particle sizes (Schreiner et al., 1999). In addition, the Schreiner lens focuses different particle sizes to different radial locations (Schreiner et al., 1999), much like SN10 shown in Fig. 5a, and is not compatible with the detection geometry in the AMS.

The aerosol time-of-flight mass spectrometer (ATOFMS, previously marketed by TSI) used an aerodynamic focusing inlet to transmit particles between $100 \mathrm{~nm}$ and $3 \mu \mathrm{m}$ in diameter with close to $100 \%$ efficiency, according to the product literature (TSI, 2004). A detailed characterization of the transmission efficiency of this inlet over its full size range has not been published.

\section{Conclusions}

A newly designed and characterized lens system for the AMS transmits particles between $80 \mathrm{~nm}$ and at least $3 \mu \mathrm{m}$ in diameter. Relative to the standard lens in common use in current AMS instruments, major design changes include (1) redesigning the critical orifice holder and valve to remove impaction sites, (2) introducing a relaxation chamber that improves the transmission of large particles, and (3) increasing the operating pressure of the lens to improve the focusing of large particles. The increased lens pressure was the primary cause of increased transmission for particles larger than $1 \mu \mathrm{m}$ in diameter, while the relaxation chamber increased the transmission of particles larger than $2 \mu \mathrm{m}$ in diameter. The design was optimized with CFD model calculations, and the lens was characterized experimentally with size-selected particles. The new lens will enable ambient $\mathrm{PM}_{2.5}$ measurements by the AMS and will open new areas of application such as drug delivery aerosols and biological particles. The new lens will also be useful for other instruments that require a focused particle beam.
Acknowledgements. This project was supported by the NSF Small Business Innovation Research Program, contract \#0216220, the EPA Small Business Innovation Research Program, contract \#EP-D-05-057, the DOE Small Business Innovation Research Program, contract \#DE-SC0001673, and the NASA Small Business Innovation Research Program, contract \#NNX10CA32C. K. Moore and J. McInnis were supported by the US DOE GCEP SURE program. M. Farrar was supported by the NSF RET program. The Aerodyne authors thank W. Guenther at the Paul Scherrer Institute, Switzerland, for assistance with the machining details.

Edited by: P. Herckes

\section{References}

Allan, J. D., Coe, H. N., Bower, K., Williams, P. I., Gallagher, M. W., Alfarra, M. R., Jiménez, J. L., Worsnop, D. R., Jayne, J. T., Canagaratna, M. R., Nemitz, E., and McDonald, A. G.: Quantitative sampling using an Aerodyne aerosol mass spectrometer 1. Techniques of data interpretation and error analysis, J. Geophys. Res., 108, 4090, doi:4010.1029/2002JD002358, 2003.

ANSYS Fluent: available at: http://www.ansys.com/ (last access: 6 June 2012), 2012.

Canagaratna, M. R., Jayne, J. T., Jiménez, J. L., Allan, J. D., Alfarra, M. R., Zhang, Q., Onasch, T. B., Drewnick, F., Coe, H., Middlebrook, A., Delia, A., Williams, L. R., Trimborn, A. M., Northway, M. J., DeCarlo, P. F., Kolb, C. E., Davidovits, P., and Worsnop, D. R.: Chemical and Microphysical Characterization of Ambient Aerosols with the Aerodyne Aerosol Mass Spectrometer, Mass. Spectrom. Rev., 26, 185-222, 2007.

Cross, E. S., Slowik, J. G., Davidovits, P., Allan, J. D., Worsnop, D. R., Jayne, J. T., Lewis, D. K., Canagaratna, M., and Onasch, T. B.: Laboratory and ambient particle density determinations using light scattering in conjunction with aerosol mass spectrometry, Aerosol Sci. Tech., 41, 343-359, doi:10.1080/02786820701199736, 2007.

DeCarlo, P., Slowik, J. G., Worsnop, D. R., Davidovits, P., and Jiménez, J. L.: Particle Morphology and Density Characterization by Combined Mobility and Aerodynamic Diameter Measurements. Part 1: Theory, Aerosol Sci. Tech., 38, 1185-1205, doi:10.1080/027868290903907, 2004.

Hinds, W. C.: Aerosol Technology: Properties, Behavior, and Measurements of Airborne Particles, John Wiley \& Sons, Inc., New York, 1999.

Huffman, J. A., Jayne, J. T., Drewnick, F., Aiken, A. C., Onasch, T., Worsnop, D. R., and Jiménez, J. L.: Design, Modeling, Optimization, and Experimental Tests of a Particle Beam Width Probe for the Aerodyne Aerosol Mass Spectrometer, Aerosol Sci. Tech., 39, 1143-1163, doi:10.1080/02786820500423782, 2005.

Jayne, J. T., Leard, D. C., Zhang, X., Davidovits, P., Smith, K. A., Kolb, C. E., and Worsnop, D. R.: Development of an Aerosol Mass Spectrometer for Size and Composition Analysis of Submicron Particles, Aerosol Sci. Tech., 33, 49-70, 2000.

Jiménez, J. L., Jayne, J. T., Shi, Q., Kolb, C. E., Worsnop, D. R., Yourshaw, I., Seinfeld, J. H., Flagan, R. C., Zhang, X., Smith, K. A., Morris, J., and Davidovits, P.: Ambient aerosol sampling using the Aerodyne Aerosol Mass Spectrometer, J. Geophys. Res., 108, 8425, doi:8410.1029/2001JD001213, 2003. 
Lee, K.-S., Kim, S., and Lee, D.: Aerodynamic focusing of 5-50 nm nanoparticles in air, J. Aerosol Sci., 40, 1010-1018, 2009.

Lee, K.-S., Hwang, T.-H., Kim, S.-W., Kim, S. H., and Lee, D.: Numerical Simulations on Aerodynamic Focusing of Particles in a Wide Size Range of $30 \mathrm{~nm}-10 \mu \mathrm{m}$, Aerosol Sci. Tech., 47, 10011008, 2013.

Liu, P., Ziemann, P. J., Kittleson, D. B., and McMurry, P. H.: Generating particle beams of controlled dimensions and divergence: I. Theory of particle motion in aerodynamic lenses and nozzle expansions, Aerosol Sci. Tech., 22, 293-313, 1995 a.

Liu, P., Ziemann, P. J., Kittleson, D. B., and McMurry, P. H.: Generating particle beams of controlled dimensions and divergence: II. Experimental Evaluation of Particle Motion in Aerodynamic Lenses and Nozzle Expansions, Aerosol Sci. Tech. , 22, 314-324, 1995b.

Liu, P. S. K., Deng, R., Smith, K. A., Jayne, J. T., Williams, L. R., Canagaratna, M. R., Moore, K., Onasch, T. B., Worsnop, D. R., and Deshler, T.: Transmission Efficiency of an Aerodynamic Focusing Lens System: Comparison of Model Calculations and Laboratory Measurements for the Aerodyne Aerosol Mass Spectrometer, Aerosol Sci. Tech., 41, 721-733, 2007.

Matthew, B. M., Middlebrook, A. M., and Onasch, T. B.: Collection Efficiencies in an Aerodyne Aerosol Mass Spectrometer as a Function of Particle Phase for Laboratory Generated Aerosols, Aerosol Sci. Tech., 42, 884-898, 2008.

Onasch, T. B., Trimborn, A., Fortner, E. C., Jayne, J. T., Kok, G. L., Williams, L. R., Davidovits, P., and Worsnop, D.: Soot Particle Aerosol Mass Spectrometer: Development, Validation, and Initial Application, Aerosol Sci. Tech., 46, 804-817, doi:10.1080/02786826.2012.663948, 2012.
Peck, J., Gonzalez, L., Williams, L., Worsnop, D. R., Miake-Lye, R. C., Smith, K. A., and Timko, M. T.: Development of an Aerosol Mass Spectrometer Lens System for PM2.5, Aerosol Sci. Technol., in preparation, 2013.

Quinn, P. K., Bates, T. S., Coffman, D., Onasch, T. B., Worsnop, D., Baynard, T., de Gouw, J. A., Goldan, P. D., Kuster, W. C., Williams, E., Roberts, J. M., Lerner, B., Stohl, A., Pettersson, A., and Lovejoy, E. R.: Impacts of sources and aging on submicrometer aerosol properties in the marine boundary layer across the Gulf of Maine, J. Geophys. Res., 111, D23S36, doi:10.1029/2006JD007582, 2006.

Schreiner, J., Schild, U., Voigt, C., and Mauersberger, K.: Focusing of Aerosols into a Particle Beam at Pressures from 10 to 150 Torr, Aerosol Sci. Tech., 31, 373-382, 1999.

TSI: Series 3800 Aerosol Time-of-Flight Mass Spectrometers with Aerodynamic Focusing Lens Technology, available at: www.tsi. com (last access: 10 February 2013), 2004.

Wang, X. and McMurry, P. H.: A Design Tool for Aerodynamic Lens Systems, Aerosol Sci. Tech., 40, 320-334, 2006.

Zhang, X., Smith, K. A., Worsnop, D. R., Jiménez, J., Jayne, J. T., and Kolb, C. E.: A Numerical Characterization of Particle Beam Collimation by an Aerodynamic Lens-Nozzle System. Part 1, An Individual Lens or Nozzle, Aerosol Sci. Tech., 36, 617-631, 2002.

Zhang, X., Smith, K. A., Worsnop, D. R., Jiménez, J. L., Jayne, J. T., Kolb, C. E., Morris, J., and Davidovits, P.: Numerical Characterization of Particle Beam Collimation: Part II Integrated Aerodynamic Lens-Nozzle System, Aerosol Sci. Tech., 38, 619-638, 2004. 